\title{
THE DETERMINATION OF THE STOICHIOMETRY OF THE MIXED COMPLEX OF VANADIUM WITH HYDROGEN PEROXIDE AND WITH 4-(2-PYRIDILAZO) RESORCINOL
}

\author{
Xiwen He \\ Department of Chemistry - Nankai University - Weijin Road - Tianjin 300071 - China \\ Matthieu Tubino* and Adriana Vitorino Rossi \\ Instituto de Química - UNICAMP - CP 6154 - 13083-970 Campinas - SP \\ Recebido em 15/4/99; aceito em 24/9/99
}

\begin{abstract}
The present study reports details of the stoichiometric characterization of the mixed complex system, $\mathrm{V}\left(\mathrm{H}_{2} \mathrm{O}_{2}\right) \mathrm{PAR}$, formed when vanadium adequately reacts with hydrogen peroxide and with 4-(2-Pyridilazo)Resorcinol. Also the presence of polynuclear species was investigated in order to elucidate about unambiguous assignment of the molar absorptivity, stability constant and composition of the complex. Two mathematical treatments methods of the experimental results were employed. From the results it can be concluded that this system corresponds to a mononuclear complex with 1:1:1 stoichiometry.
\end{abstract}

Keywords: vanadium; PAR; $\mathrm{H}_{2} \mathrm{O}_{2}$; complex stoichiometry.

\section{INTRODUCTION}

Vanadium forms a very pale complex with $\mathrm{H}_{2} \mathrm{O}_{2}$ in acid medium $\left(\varepsilon_{450-455 \mathrm{~nm}}=25\right.$ to $280 \mathrm{~L} \mathrm{~mol}^{-1} \mathrm{~cm}^{-1}, \varepsilon_{350 \mathrm{~nm}}=610$ $\left.\mathrm{L} \mathrm{mol}^{-1} \mathrm{~cm}^{-1}\right)^{1,2}$. Therefore this reaction is not sensitive enough to be used for the determination of small amounts of vanadium. On the other hand, PAR, 4-(2-Pyridylazo) Resorcinol, is known as a spectrophotometric reagent that produces a sensitive color reaction with vanadium, a red complex $\left(\lambda_{\max }=545 \mathrm{~nm}\right)$, with a $1: 1$ stoichoimetry, which maximum color intensity is observed at $\mathrm{pH}$ from 5 to $6.5^{3}$. Its high molar absorptivity $\left(\varepsilon_{545 \mathrm{~nm}}=3.45 \xi 10^{4} \mathrm{~L} \mathrm{~mol}^{-1} \mathrm{~cm}^{-1}\right)^{4-6}$ permits the determination of low concentrations of vanadium from 0.1 to $1.2 \mu \mathrm{g} \mathrm{mL}^{-1}$. However several ions interfere and must be carefully removed ${ }^{4}$.

An efficient way for increasing selectivity and sensitivity of vanadium quantitative analysis is the formation of a mixed ligand complex as it was applied for the spectrophotometric determination of total vanadium using the $\mathrm{V} / \mathrm{H}_{2} \mathrm{O}_{2} /$ PAR system ${ }^{3,7-10}$. When vanadium ions are treated with PAR in the presence of $\mathrm{H}_{2} \mathrm{O}_{2}$ in $\mathrm{H}_{2} \mathrm{SO}_{4} 0.5 \mathrm{~mol} \mathrm{~L}^{-1}$, a new red colored species with absorption maximum at $542 \mathrm{~nm}$ is formed. Although the good analytical performance of this system, it is not clear what kind of species is formed in this reaction but for analytical purposes it can be considered as a mixed complex $\mathrm{V}\left(\mathrm{H}_{2} \mathrm{O}_{2}\right) \mathrm{PAR}^{5,8-10}$.

The present study reports details of the stoichiometric characterization of the system $\mathrm{V} / \mathrm{H}_{2} \mathrm{O}_{2} / \mathrm{PAR}$ and the investigation of the presence of polynulear species in order to elucidate about unambiguous assignment of the molar absorptivity, stability constant and composition of the complex. The successful selective and sensitive analytical determination of total amount of vanadium in steels using this complex has been already reported ${ }^{10}$.

In this work, two mathematical models were used to investigate the stoichiometry and the possible presence of polynuclear complex species in order to obtain the true molecular formula, the true molar absorptivity and the true formation constant.

The reaction of hydrogen peroxide with vanadium $(\mathbf{V})$ leads to a species that can be represented as $\operatorname{VO}\left(\mathrm{O}_{2}\right)^{+2}$. Therefore, the reaction of this species with PAR is supposed to form a complex

\footnotetext{
*e-mail: tubino@iqm.unicamp.br, adriana@iqm.unicamp.br
}

that could be represented as $\mathrm{VO}\left(\mathrm{O}_{2}\right) \mathrm{PAR}$. For simplification purposes, the following representations will be used $\mathrm{V}\left(\mathrm{H}_{2} \mathrm{O}_{2}\right)$, $\mathrm{V}(\mathrm{PAR})$ and $\mathrm{V}(\mathrm{PAR}) \mathrm{H}_{2} \mathrm{O}_{2}$. Also, for simplicity the vanadium(V), $\mathrm{V}(\mathbf{V})$, will be represented only as vanadium or $\mathrm{V}$ in this text.

\section{EXPERIMENTAL}

\section{Equipments and reagents}

Absorbance measurements were made with a Hewlett Packard HP 8452A diode array spectrophotometer and a Micronal B 382 spectrophotometer, using glass cells with a $1.00 \mathrm{~cm}$ optical path length.

All reagents used were of analytical grade. Standardization was used when recommended. Water was distilled in glass equipment and deionized in a Milli Qplus Ultra Pure Water System.

A $1.00 \times 10^{-1} \mathrm{~mol} \mathrm{~L}^{-1}$ vanadium solution was prepared by dissolving $1.1688 \mathrm{~g}$ of $\mathrm{NH}_{4} \mathrm{VO}_{3}$ (Merck) and boiling with a slight excess of $\mathrm{NaOH}$ (Nuclear). The solution was cooled to room temperature and diluted to $100.0 \mathrm{~mL}$ with water. Working solutions were obtained by appropriate dilutions of this stock solution. The PAR solutions were prepared daily by dissolving the right amount of 4-(2-Pyridylazo) Resorcinol monosodium salt hydrate (Aldrich) in water. The $\mathrm{H}_{2} \mathrm{O}_{2}$ solutions were prepared by dilution of the $30 \% \mathrm{w} / \mathrm{v}_{2} \mathrm{O}_{2}$ (Merck) with water. The $\mathrm{H}_{2} \mathrm{SO}_{4}$ solutions were prepared by appropriate dilutions of the acid (Carlo Erba) with water.

\section{Procedure}

The solutions of vanadium, PAR, $\mathrm{H}_{2} \mathrm{O}_{2}$ and $\mathrm{H}_{2} \mathrm{SO}_{4}$, in different concentrations were mixed and the absorbance of the complex solution obtained was monitored spectrophotometrically, using as blank a mixture containing all the reagents solutions except vanadium, at the correspondant concentrations.

\section{RESULTS AND DISCUSSION}

\section{Complex formation}

It has been observed that the $\mathrm{V}\left(\mathrm{H}_{2} \mathrm{O}_{2}\right)$ complex, at $\mathrm{pH}=1$ (sulfuric acid medium), can be converted into a new colored 
species assumed as a mixed complex with good selectivity by adding a complexing agent as PAR [8], that can be represented as $\mathrm{V}(\mathrm{PAR}) \mathrm{H}_{2} \mathrm{O}_{2}$.

The maximum molar absorptivity, $\varepsilon$, of the red colored species formed when vanadium ions are treated with PAR in the presence of $\mathrm{H}_{2} \mathrm{O}_{2}$ in $\mathrm{H}_{2} \mathrm{SO}_{4} 0.5 \mathrm{~mol} \mathrm{~L}^{-1}$ is $1.85 \times 10^{4} \mathrm{~L} \mathrm{~mol}^{-1} \mathrm{~cm}^{-1}$ at $542 \mathrm{~nm}$. The Fig. 1 shows the spectra of $\mathrm{V}(\mathrm{PAR}) \mathrm{H}_{2} \mathrm{O}, \mathrm{V}\left(\mathrm{H}_{2} \mathrm{O}_{2}\right)$ and $\mathrm{V}(\mathrm{PAR})$ complexes in $\mathrm{pH}=1.0$ where it can be observed the higher molar absorptivity of the mixed complex.

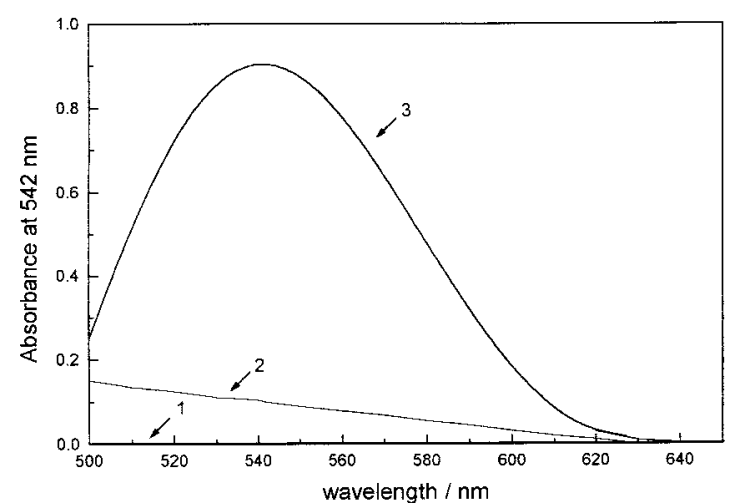

Figure 1. Visible absorption spectra of the systems: (1) $\mathrm{V}^{\mathrm{H}_{2} \mathrm{O}_{2}}$; (2) V/PAR; (3) V/PAR/ $\mathrm{H}_{2} \mathrm{O}_{2}$. [Vanadium] $=5.0 \times 10^{-5} \mathrm{~mol} \mathrm{~L} L^{-1} ;[P A R]=$ $2.5 \times 10^{-4}$ mol $L^{-1}$; concentration of $\mathrm{H}_{2} \mathrm{O}_{2}=0.15 \% \mathrm{w} / \mathrm{v}$. All solutions were prepared in $\left[\mathrm{H}_{2} \mathrm{SO}_{4}\right]=0.5 \mathrm{~mol} \mathrm{~L}$.

In a previous work ${ }^{8}$ it has been reported the existence of a single complex for this system 1:1:1 stoichiometry as ratio of $\mathrm{V}(\mathrm{PAR}) \mathrm{H}_{2} \mathrm{O}_{2}$. Although the methods of the mole ratio, the continuous variation and of the triangular diagram can yield combining ratio of vanadium to ligands, they do not indicate the true composition of the molecular formula and if polynuclear species are present. In order to determine the composition formula, two mathematical model methods were applied for differentiating mononuclear and polynuclear complexes from where it can be deduced the molecular formula.

(1) First mathematical treatment for yielding the total number of units of the vanadium and of the ligand in the complex ${ }^{11}$

A known aliquot of vanadium solution was treated preliminary with an excess of hydrogen peroxide to form the $\mathrm{V}\left(\mathrm{H}_{2} \mathrm{O}_{2}\right)$ complex $^{1,2}$. Under these conditions, upon the addition of the third reagent, PAR, a red complex is formed. The reaction producing the mixed ligand is assumed to be the general equilibrium:

$\mathbf{m} \mathrm{V}\left(\mathrm{H}_{2} \mathrm{O}_{2}\right)+\mathbf{m}$ PAR $\rightleftharpoons \mathrm{V}_{\mathrm{m}}(\mathrm{PAR})_{\mathrm{m}}\left(\mathrm{H}_{2} \mathrm{O}_{2}\right)_{\mathrm{m}}$
The combining ratio of the components $\mathrm{V}, \mathrm{H}_{2} \mathrm{O}_{2}$ and PAR in the complex were determined in a previous work ${ }^{12}$ as $(1: 1: 1)$.

Let $\mathbf{a}$ and $\mathbf{b}$ be the initial concentrations of vanadium and PAR respectively, chosen so that $\mathbf{a} / \mathbf{b}=1$.

If an optical path of $1.00 \mathrm{~cm}$ is considered, the complex reagent concentrations at equilibrium will be:

$\mathrm{V}_{\mathrm{m}}(\mathrm{PAR}){ }_{\mathrm{m}}\left(\mathrm{H}_{2} \mathrm{O}_{2}\right)_{\mathrm{m}}=\mathbf{A} / \varepsilon$

$\left[\mathrm{V}\left(\mathrm{H}_{2} \mathrm{O}_{2}\right)\right]=\mathbf{a}-\mathbf{m} \cdot(\mathbf{A} / \varepsilon)$

As $\mathbf{b}=\mathbf{a}: \quad[\mathrm{PAR}]=\mathbf{b}-\mathbf{m} \cdot(\mathbf{A} / \varepsilon)=\mathbf{a}-\mathbf{m}(\mathbf{A} / \varepsilon)=\left[\mathrm{V}\left(\mathrm{H}_{2} \mathrm{O}_{2}\right)\right]$

where $\mathbf{A}$ is the absorbance and $\varepsilon$ is the molar absorptivity of the complex $\mathrm{V}_{\mathrm{m}}(\mathrm{PAR})_{\mathrm{m}}\left(\mathrm{H}_{2} \mathrm{O}_{2}\right)_{\mathrm{m}}$.

The conditional formation constant for the reaction, $\mathrm{K}_{\mathrm{c}}$, is:

$\mathrm{K}_{\mathrm{c}}=\left[\left(\mathrm{V}_{\mathrm{m}}(\mathrm{PAR})_{\mathrm{m}}\left(\mathrm{H}_{2} \mathrm{O}_{2}\right)_{\mathrm{m}}\right] /\left(\left[\mathrm{V}\left(\mathrm{H}_{2} \mathrm{O}_{2}\right)\right]^{\mathrm{m}}[\mathrm{PAR}]^{\mathrm{m}}\right)\right.$

Substituting the above values into eq. 1 for the complex $\mathrm{V}_{\mathrm{m}}(\mathrm{PAR})_{\mathrm{m}}\left(\mathrm{H}_{2} \mathrm{O}_{2}\right)_{\mathrm{m}}$ and then simplifying, gives:

$\mathrm{K}_{\mathrm{c}}=(\mathbf{A} / \varepsilon) /\left[\mathrm{V}\left(\mathrm{H}_{2} \mathrm{O}_{2}\right)\right]^{2 \mathrm{~m}}$

which on rearrangement and expressing in logarithmic form becomes:

$\log \mathbf{A}=\log \left(\mathrm{K}_{\mathrm{c}} \varepsilon\right)+\mathbf{2 m} \log \left[\mathrm{V}\left(\mathrm{H}_{2} \mathrm{O}_{2}\right)\right]$

The first term on the right is a constant, so that a plot of $\log$ A versus $\log \left[\mathrm{V}\left(\mathrm{H}_{2} \mathrm{O}_{2}\right)\right]$ will be a straight line with slope equal to $\mathbf{2 m}$. The slope gives the total number of ligand units in the complex, from which the true molecular formula can be obtained if the empirical formula is known.

For different values of $\mathbf{a}$ and $\mathbf{b}$, keeping $\mathbf{a} / \mathbf{b}=1$, the $\left[\mathrm{V}\left(\mathrm{H}_{2} \mathrm{O}_{2}\right)\right]$ changes and can be calculated from the equation 4 .

$\left[\mathrm{V}\left(\mathrm{H}_{2} \mathrm{O}_{2}\right)\right]=\mathbf{a}-\mathbf{A} / \varepsilon^{\prime}$

where $\varepsilon^{\prime}$ is the apparent molar absorptivity of the complex.

In a first approximation if $\mathbf{m}$ is assumed to be $1, \varepsilon$ ' becames $1.85 \times 10^{4} \mathrm{~L} \mathrm{~mol}^{-1} \mathrm{~cm}^{-1}$.

Absorbance data and calculated results for solutions containing equimolar amounts of vanadium and PAR are shown in Table 1. A plot of $-\log \mathbf{a} v s-\log \left(\mathbf{a}-\mathbf{A} / \varepsilon^{\prime}\right)$ results in a straight line as can be seen in Fig. 2, fitting the equation $\log \mathbf{A}$ $=(9.47 \pm 0.23)+(2.10 \pm 0.05) \log \left[\mathrm{V}\left(\mathrm{H}_{2} \mathrm{O}_{2}\right)\right]$, with a correlation coefficient of 0.9987 . As the slope is $\mathbf{2} \mathbf{m}$ and this value is 2.10 , the value of $\mathbf{m}$ is 1.05 , or approximately 1 .

If in sequence $\mathbf{m}$ is considered as 2 , the slope obtained is 1.60. This value is incoherent because in these case $\mathbf{m}=0.80$,

Table 1. Data of the Vanadium / PAR / $\mathrm{H}_{2} \mathrm{O}_{2}$ system with $0.50 \mathrm{~mol} \mathrm{~L}-1 \mathrm{H}_{2} \mathrm{SO}_{4}$ and $0.15 \%$ w/v $\mathrm{H}_{2} \mathrm{O}_{2}$ at $28.0 \pm 0.5{ }^{\circ} \mathrm{C}$ for the first mathematical treatment.

\begin{tabular}{ccccc}
\hline $\begin{array}{c}\mathbf{a} * \\
\left(10^{-5} \mathrm{~mol} \mathrm{~L}^{-1}\right)\end{array}$ & $\mathbf{A} * *$ & $-\log \mathbf{A}$ & $-\log \left(\mathbf{a}-\mathbf{A} / \varepsilon^{\prime}\right) * * *$ & \\
\hline 1.0 & 0.050 & 1.310 & 5.135 & 4.70 \\
2.0 & 0.142 & 0.848 & 4.914 & 4.72 \\
3.0 & 0.260 & 0.585 & 4.804 & 4.77 \\
4.0 & 0.385 & 0.415 & 4.731 & 4.79 \\
5.0 & 0.509 & 0.293 & 4.647 & 4.74 \\
6.0 & 0.651 & 0.186 & 4.606 & 4.77 \\
7.0 & 0.768 & 0.114 & 4.559 & 4.75 \\
\hline
\end{tabular}

$* \mathbf{a}=\mathbf{b}=[$ vanadium $]=[\mathrm{PAR}] ; * \boldsymbol{A}=$ absorbance at $542 \mathrm{~nm} ; * * * \varepsilon^{\prime}=$ molar absorptivity of the complex assuming that it is mononuclear; $* * * * \mathrm{~K}_{\mathrm{c}}=$ formation constant of the complex. 


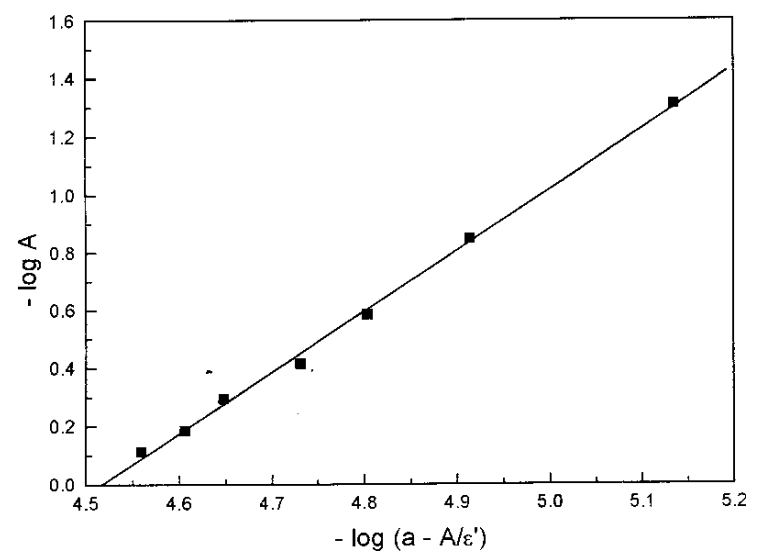

Figure 2. Correlation between the $-\log A$ and the $-\log \left(\boldsymbol{a}-\boldsymbol{A} / \mathcal{E}^{\prime}\right)$ where $\boldsymbol{a}=$ [vanadium], A is the absorbance at $542 \mathrm{~nm}$ and $\boldsymbol{\varepsilon}$ is the molar absorptivity of the complex, assuming $m=1$. Concentration of $\mathrm{H}_{2} \mathrm{O}_{2}$ is $0.15 \% \mathrm{w} / \mathrm{v} ;\left[\mathrm{H}_{2} \mathrm{SO}_{4}\right]=0.5 \mathrm{~mol} \mathrm{~L}{ }^{-1}$; ionic strength $=0.01 \mathrm{~mol} \mathrm{~L}^{-1}(\mathrm{KCl})$. Temperature $=28.0 \pm 0.5{ }^{\circ} \mathrm{C}$.

that is far from an integer number, so it was discarded. Therefore the value $\mathbf{m}=1$ was considered as the true and the specie $\mathrm{V}_{\mathrm{m}}(\mathrm{PAR})_{\mathrm{m}}\left(\mathrm{H}_{2} \mathrm{O}_{2}\right)_{\mathrm{m}}$ was admitted as mononuclear, i.e. $\mathrm{V}(\mathrm{PAR}) \mathrm{H}_{2} \mathrm{O}_{2}$.

The values of $\mathrm{K}_{\mathrm{c}}$ used in Table 1 were calculated using equation 1 from which was obtained an average value of log $\mathrm{K}_{\mathrm{c}}=4.75 \pm 0.02$ at ionic strength $=0.01 \mathrm{~mol} \mathrm{~L}^{-1}(\mathrm{KCl})$. This value can be also obtained from the intercept of the straight line of the Fig. 2. However, as experimental values of $\log$ $\left[\mathrm{V}\left(\mathrm{H}_{2} \mathrm{O}_{2}\right)\right]$ fall in the region from -4 to -5 , very far from the intercept of the y axis, graphical extrapolation to $\log \left(\left[\mathrm{V}\left(\mathrm{H}_{2} \mathrm{O}_{2}\right)\right]\right.$ $=0$ can be expected to yield large error in the value of $\mathrm{K}_{\mathrm{c}}$.

\section{(2) Second mathematical treatment: graphical method ${ }^{13}$}

In order to confirm the results of the first mathematical treatment, a second one was performed.

As done in the previous mathematical treatment, in the presence of large amounts of $\mathrm{H}_{2} \mathrm{O}_{2}$, the general equilibrium (I) can be assumed.

The degree of complex formation, $\alpha$, can be defined by:

$\alpha=\left\{\mathbf{m}\left[\mathrm{V}_{\mathrm{m}}(\mathrm{PAR})_{\mathrm{m}}\left(\mathrm{H}_{2} \mathrm{O}_{2}\right)_{\mathrm{m}}\right]\right\} / \mathbf{a}=\mathbf{A} / \mathbf{A}_{\max }$

where $\mathbf{a}=$ total vanadium concentration $=$ total $\mathrm{PAR}$ concentration; $\mathbf{A}=$ absorbance of the complex under the experimental constraints; $\mathbf{A}_{\max }$ is the absorbance of the complex for $100 \%$ complexation of vanadium ion.

Under the experimental constraints, $\left[\mathrm{V}\left(\mathrm{H}_{2} \mathrm{O}_{2}\right)\right]=[\mathrm{PAR}]$ and $\left[\mathrm{V}\left(\mathrm{H}_{2} \mathrm{O}_{2}\right)\right]=\mathbf{a}(1-\alpha)$, the rearrangement of eq. 5 gives:

$\left[\mathrm{V}_{\mathrm{m}}(\mathrm{PAR})_{\mathrm{m}}\left(\mathrm{H}_{2} \mathrm{O}_{2}\right)_{\mathrm{m}}\right]=\mathbf{a}(\alpha / \mathbf{m})$

Combination of the above relationships with eq.1 gives:

$\mathrm{K}_{\mathrm{c}}=(\mathbf{a} \alpha) /\left(\mathbf{m} \mathbf{a}^{2 \mathrm{~m}} \cdot(1-\alpha)^{2 \mathrm{~m}}\right)$

Rearranging the eq.7 and taking of logarithms the eq. 8 is obtained:

$\log \left(\alpha /(1-\alpha)^{2 m}\right)=\log \left(\mathbf{m K}_{\mathrm{c}}\right)+(2 \mathbf{m}-1) \log \mathbf{a}$

Thus, a plot of $\log \left(\alpha /(1-\alpha)^{2 \mathrm{~m}}\right)$ vs $\log$ a yields a straight line with slope $2 \mathbf{m}-1$ and linear intercept equal to $\log \left(\mathbf{m} \mathbf{K}_{c}\right)$. Selection of different values of $\mathbf{m}$ will yield straight lines with different slopes, but only the correct value of $\mathbf{m}$ will yield a slope which is equal to the value predicted by eq.8.

Treatment of the data according to the present approach yields the results shown in Table 2 . The predicted and observed slopes agree for $\mathbf{m}=1$, according to Table 3 and Fig. 3, corresponding to the composition $\mathrm{V}(\mathrm{PAR}) \mathrm{H}_{2} \mathrm{O}_{2}$. The values of $\log \mathrm{K}_{\mathrm{c}}$ calculated from eq.7 are shown in Table 4 and the average is $4.73 \pm 0.04$, in agreement with $4.75 \pm 0.02$ found in the first mathematical treatment done above.

It is interesting to note that if the difference ( $\Delta$ slope) between the observed and the predicted slope is obtained for each $\mathbf{m}$ value, and the difference between successive $\Delta$ slope values is than taken,

Table 2. Data of the Vanadium / PAR / $\mathrm{H}_{2} \mathrm{O}_{2}$ system with $0.50 \mathrm{~mol} \mathrm{~L}{ }^{-1} \mathrm{H}_{2} \mathrm{SO}_{4}$ and $0.15 \%$ w/v $\mathrm{H}_{2} \mathrm{O}_{2}$ at $28.0 \pm 0.5{ }^{\circ} \mathrm{C}$ for the second mathematical treatment.

\begin{tabular}{|c|c|c|c|c|c|}
\hline \multirow{2}{*}{$\left(10^{-5} \stackrel{\mathbf{a}^{*}}{*} \mathrm{~mol} \mathrm{~L}^{-1}\right)$} & \multirow{2}{*}{$\log \mathbf{a}$} & \multicolumn{4}{|c|}{$\log \left(\alpha /(1-2 \alpha)^{2 \mathbf{m}}\right) * *, * * *$} \\
\hline & & $\mathbf{m}=1$ & $\mathbf{m}=2$ & $\mathbf{m}=3$ & $\mathbf{m}=4$ \\
\hline 1.0 & -5.00 & -0.301 & -0.030 & 0.241 & 0.512 \\
\hline 2.0 & -4.70 & -0.023 & 0.457 & 0.885 & 1.315 \\
\hline 3.0 & -4.52 & 0.165 & 0.680 & 1.194 & 1.708 \\
\hline 4.0 & -4.40 & 0.396 & 1.083 & 1.713 & 2.397 \\
\hline 5.0 & -4.30 & 0.450 & 1.156 & 1.861 & 2.566 \\
\hline 6.0 & -4.22 & 0.536 & 1.305 & 2.073 & 2.841 \\
\hline 7.0 & -4.15 & 0.592 & 1.401 & 2.210 & 3.019 \\
\hline
\end{tabular}

$* \mathbf{a}=[$ vanadium $]=[\mathrm{PAR}] ; * * \alpha=$ degree of complex formation, calculated from eq.5; $* * * \mathbf{m}=$ assumed values, considering $\mathrm{V}_{\mathrm{m}}(\mathrm{PAR})_{\mathrm{m}}\left(\mathrm{H}_{2} \mathrm{O}_{2}\right)_{\mathrm{m}}$

Table 3. Predicted and observed slope of the curves $\log$ a versus $\log \left(\alpha /(1-2 \alpha)^{2 \mathbf{m}}\right)$ for different assumed values of $\mathbf{m}$.

\begin{tabular}{ccccc}
\hline Assumed $\mathbf{~}{ }^{*}$ & predicted slope & Observed slope & $\Delta$ slope & $\Delta^{2}$ slope $* *$ \\
\hline 1 & 1 & 1.09 & -0.09 & 1.28 \\
3 \\
4 & 3 & 1.72 & 2.62 & 1.37 \\
\end{tabular}

$* \mathrm{~m}=$ assumed values, considering $\mathrm{V}_{\mathrm{m}}(\mathrm{PAR})_{\mathrm{m}}\left(\mathrm{H}_{2} \mathrm{O}_{2}\right)_{\mathrm{m}} ; * * \Delta^{2}$ slope $=\Delta(\text { slope })_{\mathrm{m}+1}-\Delta(\text { slope })_{\mathrm{m}}$ 


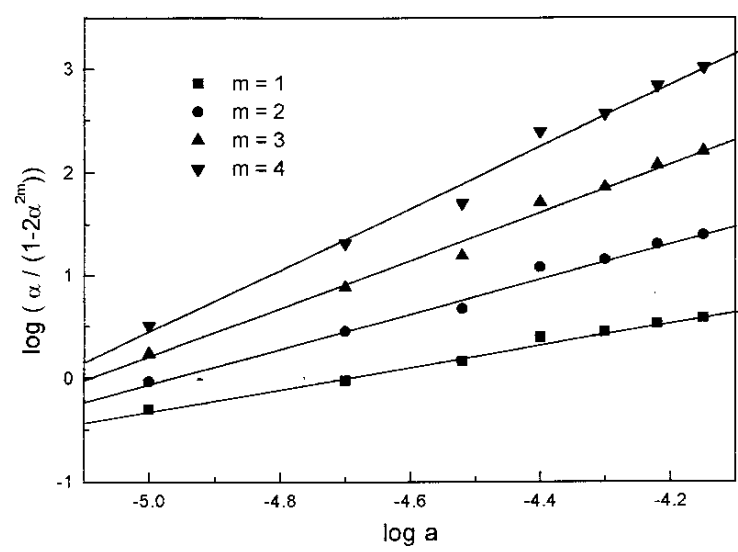

Figure 3. Correlation between the $\log \left(\alpha /(1-\alpha)^{2 m}\right)$ and $\log a$, where $\alpha$ is the absorbance due the complex for $100 \%$ complexation of vanadium. For $\boldsymbol{m}=1$, the complex is assumed as mononuclear. For $\boldsymbol{m}$ $>1$ the complex is assumed as polynuclear. Concentration of $\mathrm{H}_{2} \mathrm{O}_{2}$ is $0.15 \% \mathrm{w} / \mathrm{v} ;\left[\mathrm{H}_{2} \mathrm{SO}_{4}\right]=0.5 \mathrm{~mol} \mathrm{~L}^{-1}$; ionic strength $=0.01 \mathrm{~mol} \mathrm{~L}^{-1}(\mathrm{KCl})$. Temperature $=28.0 \pm 0.5^{\circ} \mathrm{C}$.

Table 4. $\mathrm{K}_{\mathrm{c}}$ values for the Vanadium / PAR / $\mathrm{H}_{2} \mathrm{O}_{2}$ system with $0.50 \mathrm{~mol} \mathrm{~L}^{-1} \mathrm{H}_{2} \mathrm{SO}_{4}$ and $0.15 \% \mathrm{w} / \mathrm{v} \mathrm{H}_{2} \mathrm{O}_{2}$ at $28.0 \pm 0.5{ }^{\circ} \mathrm{C}$ from the second mathematical treatment.

\begin{tabular}{cccc}
\hline $\begin{array}{c}\mathbf{a} * \\
\left(10^{-5} \mathrm{~mol} \mathrm{~L}^{-1}\right)\end{array}$ & $\mathbf{A} * *$ & $\alpha * * *$ & $\begin{array}{c}\log \mathrm{K}_{\mathrm{c}} \\
(\mathbf{m}=1)^{* * * *}\end{array}$ \\
\hline 1.0 & 0.050 & 0.268 & 4.70 \\
2.0 & 0.142 & 0.391 & 4.68 \\
3.0 & 0.260 & 0.477 & 4.77 \\
4.0 & 0.385 & 0.536 & 4.80 \\
5.0 & 0.509 & 0.556 & 4.75 \\
6.0 & 0.651 & 0.587 & 4.76 \\
7.0 & 0.768 & 0.606 & 4.74 \\
\hline \multicolumn{4}{r}{} \\
\hline
\end{tabular}

Average $\log \mathrm{K}_{\mathrm{c}}=4.73 \pm 0.02$

* $\quad \mathbf{a}=[$ vanadium $]=[\mathrm{PAR}]$

$* * \quad \mathbf{A}=$ absorbance at $542 \mathrm{~nm}$

*** $\alpha=$ degree of complex formation, calculated from eq.5

$* * * * \mathbf{m}=$ assumed values, considering $\mathrm{V}_{\mathrm{m}}(\mathrm{PAR})_{\mathrm{m}}\left(\mathrm{H}_{2} \mathrm{O}_{2}\right)_{\mathrm{m}}$

$\Delta^{2}$ slope $=\Delta(\text { slope })_{\mathrm{m}+1}-\Delta(\text { slope })_{\mathrm{m}}$

the values of $\Delta^{2}$ slope are constant (Table 3). A plot of observed slope $v s$. assumed $\mathbf{m}$ values must therefore yield a straight line of the general form

$y=i x+j$

where $y=$ observed slope, $x=$ assumed $\mathbf{m}$ values, $i$ and $j$ are the slope and the linear coefficients respectively. There can be only one correct pair of $\mathrm{x}$ and $\mathrm{y}$ values for this system, given by the equation for the predicted slope line

$\mathrm{y}=2 \mathrm{x}-1$

where in this case $\mathrm{x}=$ true $\mathbf{m}$ value and $\mathrm{y}$ is the correct predicted slope. In Fig. 4, the point of intersection of the two equations can be estimated from the graph, or calculated exactly by solving eq. 10 and eq. 11 for $x$. For the $\mathrm{V}(\mathrm{PAR}) \mathrm{H}_{2} \mathrm{O}_{2}$ system, eq. 10 is $y=0.632 x+0.460$, which yields $x=1.06=\mathbf{m}$.

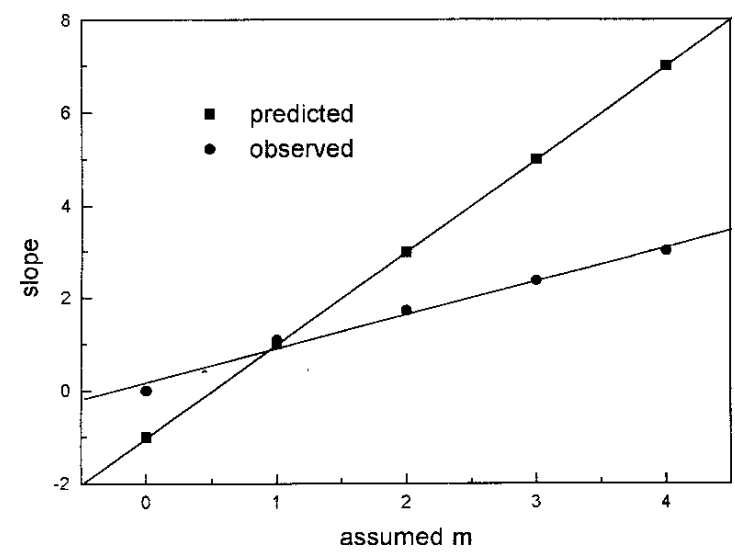

Figure 4. Correlation of observed and predicted slope values with the assumed $\boldsymbol{m}$ values. For $\boldsymbol{m}=1$, the complex is assumed as mononuclear. For $\boldsymbol{m}>1$ the complex is assumed as polynuclear.

\section{CONCLUSION}

From the above results, it is possible to conclude that a $1: 1: 1$ mixed mononuclear complex is formed as result of the reaction of vanadium with $\mathrm{PAR}$ and hydrogen peroxide in sulfuric acid medium. Therefore, the true formula of the complex can be considered as $\mathrm{V}\left(\mathrm{H}_{2} \mathrm{O}_{2}\right) \mathrm{PAR}$. The logarithm of the equilibrium constant was found to be $4.73 \pm 0.04$ or $4.75 \pm 0.02$ by two different mathematical treatments. As a consequence of the stoichiometry of the complex, the true molar absorptivity is $1.85 \times 10^{4} \mathrm{~L} \mathrm{~mol}^{-1} \mathrm{~cm}^{-1}$ at $542 \mathrm{~nm}$.

\section{ACKNOWLEDGMENTS}

The authors are grateful to Fundação de Amparo à Pesquisa do Estado de São Paulo, FAPESP, and to Conselho Nacional de Desenvolvimento Científico e Tecnológico, CNPq, for financial support.

\section{REFERENCES}

1. Palilla, F. C; Adder, N. C.; Hiskey, F.; Anal. Chem. 1953, 25,926

2. Orhanovic, M.; Wilkins, R. G.; J. Am. Chem. Soc. 1967, 89, 278.

3. Anjaneneyuiu,Y.; Reddy, M. R. P.; Kumar, P. V. S.; Kavipurapu, C. S.;Rao, B. V.; Mikrochim. Acta I 1990, 87.

4. Gagliardi, E.; Ilmaier, B.; Mikrochim. Acta 1967, 180.

5. Schneider, J.; Cs'angi,L. J.; Mikrochim. Acta II 1976, 271.

6. Chakrapani, G.; Murty, D. S. R.; Balazi, B. K.; Rangaswamy, R.; Talanta 1993, 40, 541.

7. Salinas, F.; Jimenez-Arrabal, M.; Duran Meras, I.; An. Quim., Ser. B. 1988, 99, Anal. Abs. 1988, 10B170, 50

8. Zucchi,C.; Forneris, M.; Martínez, L.; Olsina, R.; Marchevsky, E.; Fresenius J. Anal. Chem. 1998, 360, 128.

9. Taylor, M. J. C.; Marshal, G. D.; Williams, S. J. S.; van Staden, J. F.; Sailing, C.; Anal. Chim. Acta 1996, 275.

10. He, X.; Tubino, M.; Rossi, A. V.; Anal. Chim. Acta 1999, 396,275

11. He, X.; Poe, D. P.; Anal. Chim. Acta 1982, 353.

12. Shih, H. G; He, X.; Ko Hsueh Tung Pao 1965, 8, 762; Chem. Abs. 1967, 66, 34590v.

13. He, X.; Poe, D. P.; Talanta 1982, 29, 767. 